\section{Extensão e Educação a Distância em Dois Cursos de Literatura}

Extension and Distance Learning in Two Literature Courses

\section{RESUMO}

O crescimento da educação a distância e das políticas nacionais para a extensão universitária caminham para que a indissociabilidade entre ensino, pesquisa e extensão seja cada vez mais propagada e posta em prática. Nesse sentido, este artigo apresenta dados de uma experiência com a ministração de dois cursos realizados a distância em 2012 como parte do projeto de extensão Narrativas e Visualidades, do curso de Artes Visuais da Universidade Federal do Vale do São Francisco (UNIVASF). O texto apresenta a justificativa e o conteúdo para a criação dos cursos Tennessee Williams 'early work: a valuable first glance e Reading the modern drama, o perfil dos discentes de cada curso e as tecnologias da informação e da comunicação utilizadas, mencionando quais geraram bons resultados e quais não foram efetivas no decorrer das atividades. Os resultados permitem concluir que cursos de extensão a distância cujo foco é a literatura despertam maior interesse em discentes ou ex-discentes dos cursos de Letras mesmo quando não é exigida formação nessa área, e também em pessoas com formação em outras áreas de Humanidades. Além disso, verificou-se que o uso de tecnologias adequadas aos vários conteúdos aumenta a participação e a interação, considerando a necessidade e o tempo que cada item programático demanda.

Palavras-chave: Educação a Distância. Tecnologias da Informação e da Comunicação. Ensino de Literatura.

\section{ABSTRACT}

The growth of distance learning and the Brazilian policies for university extension are being conducted so that the inextricable connection of teaching, research and extension is increasingly propagated and practiced. Accordingly, this article presents data from an experience with the teaching of two distance learning courses in 2012 as part of the extension project Narrativas e Visualidades (Narratives and Visualities), of the
FULVIO TORRES

FLORES

Universidade Federal do Vale do São Francisco, Bahia, Brasil 
Course of Visual Arts at UNIVASF (Juazeiro-BA, Brazil). The paper presents the justification and content for the creation of the courses Tennessee Williams' early work: a valuable first glance and Reading the modern drama, the profile of students in each course and the information and communication technologies that have been used, which generated good results and which were not effective throughout the activities. The results show that the distance extension courses whose focus is literature arouse greater interest in students or former students of Letras (Literature and Language) even when education in this area is not required, but also in people with education in other areas of Humanities. Besides the results showed the use of technologies increasing the participation and interaction, but they need to be thought according to the content and considering the need and time they demand.

Keywords: Distance Learning. Information and Communication Technologies. Literature Teaching.

\section{INTRODUÇÃO}

O objetivo deste trabalho é relatar e discutir a experiência de ensino em educação a distância $(\mathrm{EaD})$ adquirida por meio de dois cursos de literatura lecionados em 2012, nos quais o uso das tecnologias da informação e da comunicação (TICs) permitiu um bom encaminhamento da aprendizagem e uma interação produtiva entre discentes e docente (autor deste artigo). Antes, porém, cabe situar o leitor sobre como a EaD tem sido beneficiada, desde o seu surgimento, pela capacidade de incorporar as TICs no cotidiano de ensino/aprendizagem. Desde a sua considerável expansão no século XIX, quando a $\mathrm{EaD}$ se dava por correspondência, o nível de interatividade entre discente e docente era muitíssimo baixo, pois dependia basicamente da palavra escrita trocada por cartas, nas quais ambos discutiam a sequência de estudos, realizavam e corrigiam exercícios, provas e afins. O Instituto Universal Brasileiro, a mais conhecida empresa privada de educação a distância no Brasil, fundada em 1941, surgiu no contexto da educação a distância por correspondência.

Os anos 60 trouxeram uma primeira revolução a essa modalidade de ensino, uma vez que permitiu articular o material impresso - forma predominante do ensino a distância até então - com tecnologias multimeios, como a televisão, o rádio, as fitas cassetes, o telefone etc. Insere-se neste contexto o programa Telecurso $2^{\circ}$. Grau, uma parceria da Rede Globo e TV Cultura. A interatividade era um pouco maior nessa fase, pois imagens e sons, tanto do conteúdo do curso quanto dos próprios participantes (discentes e principalmente de docentes), poderiam ser trocados, permitindo uma maior proximidade entre ambos.

Sem dúvida, foi a revolução tecnológica trazida pela expansão da rede de computadores e, em seguida, da internet, que mais tem contribuído para a ampliação e interação da $\mathrm{EaD}$ em várias partes do globo. Às tecnologias anteriores - da carta à televisão - somaram-se novas, como o e-mail, fóruns de discussão, blogs, chats, websites e, mais recentemente, as plataformas específicas de aprendizagem a distância, 
também conhecidas como AVAs - ambientes virtuais de aprendizagem - e as redes sociais, como o Facebook. Em Educação a distância, Belloni [1] afirma que:

A educação aberta e a distância aparece cada vez mais, no contexto das sociedades contemporâneas, como uma modalidade de educação extremamente adequada e desejável para atender às novas demandas educacionais decorrentes das mudanças na nova ordem econômica mundial.

É no âmbito desse terceiro fluxo que a experiência a ser relatada pertence, uma vez que o uso de AVAs e TICs serviu como base para o desenvolvimento das atividades. Os dois cursos que fazem parte desta experiência extensionista são: Tennessee Williams 'early work: a valuable first glance (Os primeiros escritos de Tennessee Williams: um valoroso primeiro olhar) e Reading the modern drama (Lendo o drama moderno). As figuras 1 e 2 abaixo mostram a "capa" dos cursos.

Tennessee Williams 'early work: a valuable first glance
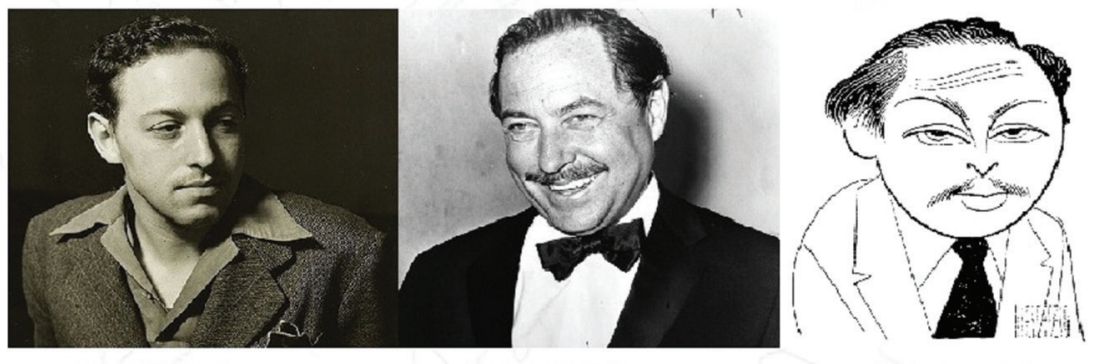

The young Tennessee

The successful Tennessee

A draving by Al Hirschfield

Aim: The study of four short stories and four one-act plays by Tennessee Wiltams in order to understand the importance and significance of his literature/dramaturgy since the begining of his career.
Figura 1 - Capa do curso Tennessee Williams' early work: a valuable first glance, por meio da qual são mostradas três imagens do escritor norte-americano Tennessee Williams: a primeira enquanto jovem, antes de alcançar o sucesso; a segunda já um autor consagrado; e a terceira um desenho de Al Hirschfield, importante ilustrador do The New York Times. Montagem feita pelo autor do artigo.

Como entre as leituras do curso Tennessee Williams' early work: a valuable first glance estavam alguns textos em inglês, procurou-se divulgá-lo com o título nessa língua, evitando, assim, a inscrição de pessoas sem conhecimentos intermediários, uma vez que não realizariam a leitura dos contos, das peças em um ato e textos teóricos de forma devida. Logo no início foi permitido aos discentes que participassem dos chats e fóruns em língua portuguesa ou inglesa, a critério de cada um. Poucos se interessaram em usar a língua inglesa na comunicação com os colegas e o docente e em poucas semanas a comunicação era toda mantida em língua portuguesa.

O curso Reading the modern drama, por sua vez, foi divulgado como curso bilíngue, ficando claro aos discentes que eles poderiam se expressar em qualquer uma das duas línguas e que haveria leituras a serem realizadas em língua inglesa. Desde o início, por opção dos discentes, toda a comunicação foi mantida em língua portuguesa.

Retornando à questão das tecnologias, o ganho no uso das TICs em AVAs consiste principalmente na forma como elas podem ajudar a incentivar os processos de comunicação e pesquisa, tirando do foco o conteudismo (aprender quantitativo) e trocando-o por um saber qualitativo, além de permitir que os discentes não fiquem 
Figura 2 - Capa do curso Reading the modern drama em que é mostrada uma foto

da encenação da peça Casa

de bonecas, de lbsen, em adaptação intitulada Nossa Casa de Bonecas. Na figura é notável a personagem Nora Torvald, interpretada por Teth Maiello. Imagem do website da Companhia Teatro de Narradores

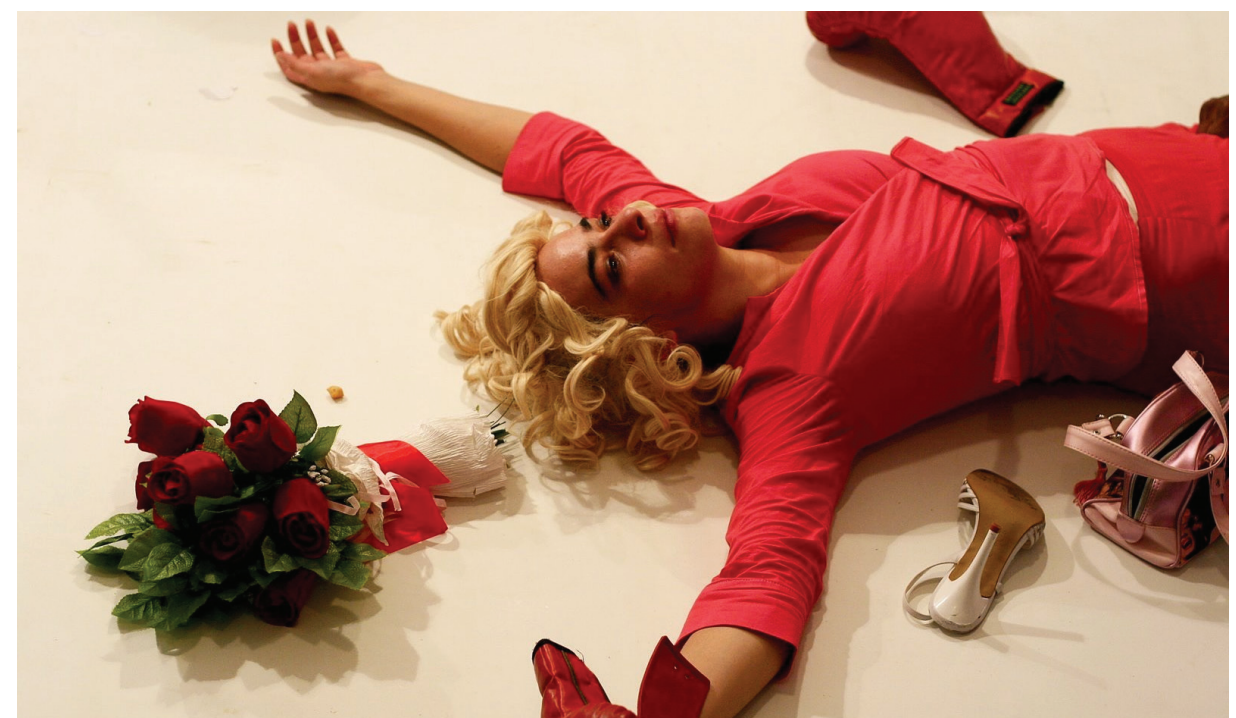

presos a horários fixos de participação. Porém, deve-se manter o foco no objetivo estabelecido e na compreensão de conceitos que envolvem o tema em discussão, caso contrário corre-se o risco de cair na tentação do uso indiscriminado do excesso de fontes disponíveis na rede, o que pode acarretar justamente o que se tenta evitar nesta modalidade de ensino, a saber, a superficialidade [2].

Não se pode deixar de explicitar nesta introdução que, segundo a Política Nacional de Extensão Universitária, a extensão deve ser entendida “[...] de forma indissociável com o Ensino e a Pesquisa, com vistas à promoção e garantia dos valores democráticos, da equidade e do desenvolvimento da sociedade em suas dimensões humana, ética, econômica, cultural, social." [3]. Com isso, a oferta desses cursos de extensão gratuitos cumpre um papel social importante porque leva para além dos muros da universidade o conhecimento que ela debate no ensino e produz na pesquisa, desenvolvendo uma interação eficaz com as práticas e saberes da sociedade.

\section{MATERIAIS E MÉTODOS}

Os materiais utilizados para o projeto foram:

a) Ambiente Virtual de Aprendizagem por meio da plataforma Moodle da Universidade Federal do Vale do São Francisco;

b) textos em versão PDF, vídeos;

c) links para websites e blogs.

Os métodos para que o projeto se efetivasse foram os seguintes:

a) Cumprimento, por parte do docente, do Curso de Modelagem e Gestão de Ambientes 
Virtuais na Plataforma Moodle, pois a dinâmica da EaD demanda uma prévia capacitação a respeito das interfaces das TICs e sobre o processo de atuação nessa modalidade. Dessa forma, fez-se necessária formação e orientação técnico-pedagógica para o ministrante. O curso foi oferecido em 2011 pela Secretaria de Educação a Distância da UNIVASF, com duração de 40 horas, lecionado pelos professores Flávia Maria de Brito Pedrosa Vasconcelos e Luciano Gomes Silva, com a seguinte estrutura:

Etapa I: introdução e aspectos históricos e legais da $\mathrm{EaD}$;

Etapa II: prática de uso da plataforma Moodle;

Etapa III: mediação e gestão do ambiente virtual de ensino;

Etapa IV: criação e modelagem de um curso proposto pelos professores.

A realização do curso foi de fundamental importância, pois as etapas contempladas foram bem distribuídas e permitiram um entendimento aprofundado dos variados aspectos relacionados à $\mathrm{EaD}$, afinal não basta saber formular um curso em uma plataforma virtual. Conhecer os aspectos históricos e legais permite vislumbrar os acertos, as falhas e as adaptações que foram feitas ao longo do tempo para que essa modalidade de educação pudesse atender a públicos cada vez mais amplos sem perder a qualidade necessária.

De todas as etapas, a prática de uso do Moodle foi a menos complexa, não apenas para o docente, mas também para a maior parte dos alunos do curso, pois essa maioria já era usuária de redes sociais e até mesmo blogs, o que facilitou muito o entendimento de aspectos técnicos da plataforma, tais como: postagens, edições, carregamento de dados, configuração HTML (linguagem de marcação de hipertexto) etc. A etapa de mediação e gestão é a mais delicada do processo, pois se trata de articular como o conteúdo de um curso pode ser trabalhado em sua potencialidade virtual máxima, a fim de usar os recursos (página de texto simples, página de texto web, links) e as atividades (fórum, chat, glossário, questionário etc.) da melhor maneira possível, prevendo como será a interação com os discentes. É claro que o ambiente virtual, assim como a sala de aula presencial, não são passíveis de completa previsibilidade, mas cabe ao professor ministrante de um curso virtual conhecer, ainda que superficialmente, o perfil do alunado para o curso, pois o uso desses recursos e atividades deverá variar conforme o público participante.

A última etapa permitiu que todo o conhecimento pertinente ao curso fosse colocado em prática, pois a atividade final foi a criação de um curso virtual de 40 horas, seguindo parâmetros indicados pelos professores. Dessa forma, o docente estava preparado para criar seus cursos e iniciar a prática de ensino em EaD.

b) Preparação de materiais para o curso: nesta etapa, o docente verificou a existência de materiais de livre circulação - como artigos científicos, livros disponíveis em websites de livre acesso (como o Google Livros), dissertações e teses, blogs, vídeos etc - e inseriu os links no AVA. Os materiais de livre circulação podem ser inseridos no ambiente, porém, livros em formato digital, músicas e imagens com detenção de direitos autorais podem gerar problemas ao administrador do Moodle (no caso, a universidade à qual o projeto é vinculado), uma vez que tais materiais não podem ser reproduzidos sem prévia 
autorização, o que inclui a reprodução virtual. Portanto, para a preparação de materiais, é preciso, além de domínio sobre o tema, conhecimento de legislação e ética, o que foi possível graças ao curso mencionado no item acima.

c) Divulgação do curso por meio de websites e redes sociais, e-mails de universidades, institutos, escolas e ONGs para que os interessados pudessem saber mais sobre o curso; foram disponibilizadas páginas específicas no website do projeto Narrativas e Visualidades - Cursos de Extensão em EaD (www.narravis.com.br). As redes sociais - especialmente o Facebook - se mostraram como a forma mais eficiente de "propagar” a divulgação dos cursos. Porém, não seria possível se restringir a elas para a divulgação, pois isso eliminaria a chance de pessoas que não participam de tais redes se matricularem nos cursos e terem a experiência com a EaD. Assim, além das redes sociais, foi de grande relevância a divulgação para as pró-reitorias de extensão das universidades brasileiras. O bolsista Pedro José Leite Ferreira e a voluntária Kathianne de Souza, discentes do curso de Artes Visuais da UNIVASF, coletaram e-mails de pró-reitorias de universidades públicas (federais e estaduais), privadas, fundações e pontifícias universidades católicas etc. Essa divulgação ajudou a atingir o público universitário, enquanto a divulgação para institutos, escolas e ONGs atingiu um público não universitário em geral.

O website Narravis foi configurado com as seguintes páginas informativas: a) inicial, apresentando o projeto; b) cursos disponíveis em cada semestre; c) relação dos cursos disponíveis com ementa, programa de curso e link para inscrição; d) equipe executora do projeto: coordenadores, professores, bolsista e voluntárias; e) links interessantes para websites relacionados à proposta do projeto; f) contato com a equipe do projeto. Assim, foi permitido aos interessados conhecer não apenas os cursos oferecidos, mas o projeto como um todo e sua equipe executora, além de uma relação de páginas que se alinham com o Narravis.

d) Seleção e inscrição dos discentes, que se deu por meio de ficha de inscrição enviada diretamente ao e-mail do docente. Procurou-se, à medida do possível, distribuir as 20 vagas de cada curso de forma a beneficiar pessoas de diferentes estados do país. Muitos candidatos à vaga foram eliminados no processo por não enviarem a carta de interesse com a ficha de inscrição. A carta de interesse era de suma importância para que o docente pudesse selecionar os discentes. Foram dadas breves instruções do que deveria conter a carta: nome, idade, profissão, nível de formação, área de formação (no caso de graduação e pós-graduação), nível de leitura em inglês, motivo de interesse pelo curso e expectativas sobre o mesmo.

Uma vez feita a seleção, a inscrição era realizada virtualmente com os dados básicos do discente (nome completo, $\mathrm{CPF}$ e cidade) no Moodle. Aos selecionados e não selecionados foram enviados e-mails (separadamente) informando sobre o resultado da seleção. Os selecionados, a partir do recebimento deste e-mail, recebiam as instruções para acesso à plataforma. 
e) Ministração dos cursos, realizada totalmente online nos meses de março a junho de 2012 (Tennessee Williams'...) e de setembro a novembro de 2012 (Reading the modern drama), cada curso com 12 semanas de duração. Essa etapa está circunstanciada a seguir na seção de Resultados e Discussão.

f) Certificação dos concluintes, realizada um mês após o término de cada curso, consistindo no envio de certificado assinado pelos coordenadores do projeto e pela pró-reitora de extensão da universidade.

\section{RESULTADOS E DISCUSSÃO}

\section{Parte 1 - Justificativa e Conteúdos}

A oferta de ambos os cursos tem relação direta com a formação em nível de pós-graduação do docente. O primeiro curso oferecido (Tennessee Williams' early work: a valuable first glance - TWEW) tomou como base estudos realizados durante o doutorado em Estudos Linguísticos e Literários em Inglês, cuja tese, finalizada em 2013, intitula-se Da Depressão às raízes do macartismo: representação de questões sócio-históricas em American blues, de Tennessee Williams [4]. Nesse curso foram discutidos quatro contos e quatro peças curtas do autor norte-americano, respectivamente: The lady's beaded bag (A bolsa aljofarada de uma senhora), Big Black: a Mississippi idyll (Negão, um idilio no Mississípi), In memory of an aristocrat (Em memória de uma aristocrata), The mysteries of the Joy Rio (Os mistérios do Joy Rio), At liberty (Em liberdade), The lady of the Larkspur lotion (A dama da loção antipiolho), Curtains for the gentleman (Cortinas para o cavalheiro) e This property is condemned (Esta propriedade está condenada).

Tennessee Williams é um autor bastante conhecido, especialmente por quem tem interesse por dramaturgia e teatro, e está no panteão dos dramaturgos do século XX. Embora tenha uma obra gigantesca, composta por mais de cem títulos, seu cânone é composto por não mais do que quatro ou cinco peças escritas em um período de 15 anos. Sua produção, no entanto, foi escrita ininterruptamente ao longo de mais de cinco décadas, sendo finalizada apenas em 1983, quando faleceu. O objetivo do curso, já explicitado em seu título, era permitir aos discentes um olhar de descoberta, contato e discussão sobre obras pouco conhecidas, algumas inclusive sequer traduzidas para livros. A vantagem de olhar para a obra desconhecida de um autor canônico é justamente poder trazer à tona a qualidade e importância dessa obra - muitas vezes desprezada ou tratada como juvenil - para um público interessado e que não está preso a julgamentos de valor antecipados.

De forma bem diversa se deu o curso Reading the modern drama (RMD), diferenciando-se do anterior por se concentrar nas obras de quatro autores canônicos de épocas e lugares distintos, os quais ajudaram a recriar o drama rompendo com regras pré-determinadas e fórmulas convencionais, a saber: Casa de bonecas (Et dukkehjem - 1879), do norueguês Henrik Ibsen; As três irmãs (Tri Sestri-1900), do russo Anton Tchekhov; Zoológico de vidro (The glass menagerie; em português também conhecida 
como À margem da vida - 1944), do norte-americano Tennessee Williams; e Mãe coragem e seus filhos (Mutter Courage und ihre Kinder - 1939), do alemão Bertolt Brecht.

Para esse curso também foi aproveitada a experiência do docente com sua tese de doutorado e retomada a pesquisa do mestrado na qual estudou duas peças da também norte-americana Lillian Hellman, na qual discutiu assuntos relacionados ao drama burguês e moderno [5]. Com uma característica fortemente panorâmica, isto é, sem se aprofundar nas temáticas e estilos de cada um dos autores, foi possível entender que o que se chama de drama moderno não é constituído de um corpo uniforme de peças, pois a libertação obtida com a quebra das regras do drama burguês permitiu modificações variadas na forma das obras, como bem tratado por Peter Szondi [6]. Assim, foram discutidos temas e formas representativos das peças, especialmente questões sócio-históricas relevantes para a compreensão das mesmas, privilegiando a leitura dos textos teatrais sem dispensar leituras e pesquisas teóricas.

\section{Parte 2 - Perfil dos Discentes}

A oferta do curso TWEW previa que os interessados, ao cursá-lo, deveriam ler alguns dos textos em língua inglesa, uma vez que não havia tradução dos mesmos (essa era a única exigência para inscrição). Todos os inscritos tinham, no mínimo, conhecimentos intermediários da língua inglesa. O perfil dos 20 discentes desse curso está organizado nas Tabelas 1, 2 e 3 abaixo:

Tabela 1 - Formação acadêmica

\begin{tabular}{lccccc}
\hline CURSO & GRADUANDOS & GRADUADOS & MESTRANDOS & MESTRES & DOUTORES \\
\hline Letras (17) & 5 & 5 & 4 & 2 & 1 \\
\hline Outros (3) & 1 & 1 & ---- & 1 & --- \\
\hline
\end{tabular}

Tabela 2 - Conhecimentos sobre literatura e atuação na área

\begin{tabular}{llll}
\hline \multirow{2}{*}{$\begin{array}{l}\text { CONHECIMENTO DE } \\
\text { LITERATURA } \\
\text { NORTE-AMERICANA } \\
\text { EM GERAL }\end{array}$} & $\begin{array}{l}\text { CONHECIMENTO } \\
\text { DA OBRA DE } \\
\text { TENNESSEE } \\
\text { WILLIAMS }\end{array}$ & $\begin{array}{l}\text { ÁREA DE ATUAÇÃO } \\
\text { RELACIONADA À } \\
\text { LITERATURA }\end{array}$ \\
\hline Letras (17) & 11 & 6 & 8 \\
\hline Outros (3) & 1 & -1 & Não se aplica \\
\hline
\end{tabular}


Tabela 3 - Estados onde os discentes moram

\begin{tabular}{lcccccccccc}
\hline ESTADO & SE & SP & PE & MT & BA & MA & RJ & PR & MG & RS \\
\hline Número de discentes & 5 & 5 & 2 & 2 & 1 & 1 & 1 & 1 & 1 & 1 \\
\hline
\end{tabular}

Sendo a única exigência conhecimentos da língua inglesa para leitura dos textos, dois fatos surpreenderam na análise dos perfis: a) a maioria dos discentes inscritos provinha da área de Letras, sendo apenas três de outras áreas (a saber, Administração, Pedagogia e História), o que ajuda a entender porque mais da metade possuía conhecimentos prévios sobre autores da literatura norte-americana e pouco mais de um quarto conhecia a obra de Tennessee Williams; b) o fato de Sergipe e São Paulo somarem o mesmo número de inscritos. Após o início do curso, descobriu-se que houve uma ampla divulgação espontânea na Universidade Federal de Sergipe, provavelmente gerando o número mais alto de inscritos em relação a outros estados em que a divulgação espontânea por parte das pró-reitorias das universidades não foi tão grande. Quanto a São Paulo, o número não surpreende devido a esse ser o estado mais populoso da nação.

Para o curso RMD, as Tabelas 4, 5 e 6 apresentam o perfil dos discentes (nos mesmos moldes das Tabelas 1, 2 e 3):

Tabela 4 - Perfil dos 20 discentes

\begin{tabular}{lcccc}
\hline CURSOS & GRADUANDOS & GRADUADOS & MESTRANDOS & MESTRES \\
\hline Letras (12) & 5 & 3 & 3 & 1 \\
\hline Pedagogia (3) & ---- & 2 & 1 & ---- \\
\hline Teatro (2) & ---- & 1 & ---- & -1 \\
\hline Outros (3) & 1 & 2 & ---- \\
\hline
\end{tabular}

Tabela 5 - Perfil de conhecimento de literatura e atuação na área

\begin{tabular}{|c|c|c|c|}
\hline CURSO & $\begin{array}{c}\text { CONHECIMENTO } \\
\text { DE DRAMATURGIA } \\
\text { UNIVERSAL }\end{array}$ & $\begin{array}{c}\text { CONHECIMENTO DAS } \\
\text { PEÇAS ESTUDADAS } \\
\text { NO CURSO }\end{array}$ & $\begin{array}{c}\text { ÁREA DE ATUAÇÃO } \\
\text { RELACIONADA À } \\
\text { LITERATURA OU AO } \\
\text { TEATRO }\end{array}$ \\
\hline Letras (17) & 11 & 6 & 8 \\
\hline Pedagogia (3) & 2 & ----- & ----- \\
\hline Teatro (2) & 2 & 2 & 2 \\
\hline Outros (3) & 2 & 1 & ----- \\
\hline
\end{tabular}


Tabela 6 - Estados dos discentes do curso Reading the modern drama

\begin{tabular}{lcccccccc}
\hline ESTADO & SP & MG & PE & MS & SE & BA & DF & GO \\
\hline Número de discentes & 7 & 3 & 3 & 2 & 2 & 1 & 1 & 1 \\
\hline
\end{tabular}

A divulgação para o curso RMD foi ampliada. Não apenas foram enviados e-mails a universidades, institutos, escolas e organizações governamentais, como também a rede social Facebook foi utilizada e demonstrou ser uma forma bastante prática e eficiente de divulgar cursos de extensão. Sendo este um curso menos específico que o anterior, nota-se claramente uma maior diversidade no perfil dos discentes no que se refere: a) aos cursos de proveniência; b) ao conhecimento prévio, pois a proveniência de diversos cursos não interferiu no grande número de conhecedores de uma ou mais obras da dramaturgia universal, sendo a provável razão todos serem cursos ligados às Humanidades. No entanto, o número de discentes que já havia tido contato com as peças estudadas no curso ficou reduzido a menos da metade.

No que se refere aos estados em que moram os discentes, houve uma redução no número de locais (de 10 para 8), mas uma distribuição mais equânime: apesar de São Paulo continuar com o número mais elevado, o que se explica pelo seu índice populacional, quatro estados ficaram com 3 e 2 discentes (contra 2 do curso anterior) e três com apenas 1 discente (contra 6 do curso anterior). Vale notar, porém, que TWEW teve discentes de todas as cinco regiões do Brasil, enquanto RMD, de apenas três (Sudeste, Nordeste e Centro-Oeste). A razão para essa diminuição não pôde ser interpretada, uma vez que a divulgação foi feita para instituições de todo o Brasil de forma similar, tanto quantitativa quanto qualitativamente.

Parte 3 - Uso das TICs

Um curso realizado a distância não pode se basear apenas na transposição de conteúdos presenciais para o ambiente virtual, pois

A apreensão do conhecimento na perspectiva das novas tecnologias eletrônicas de comunicação e informação, ao ser assumida como possibilidade didática, exige que, em termos metodológicos, também se oriente a prática docente com base em uma nova lógica. Compreender este novo mundo com uma nova lógica, uma nova cultura, uma nova sensibilidade, uma nova percepção. [7]

Partindo dessa premissa, a estratégia de uso das técnicas relacionadas às TICs para o curso TWEW foi baseada no conteúdo do próprio curso e no uso de tecnologias de fácil acesso e compreensão, inclusive porque era a primeira experiência do docente nessa modalidade de ensino. Já o curso RMD se beneficiou da experiência obtida em TWEW. Por isso foram realizadas algumas modificações, pois, como afirma Masetto, 
No contexto educacional, as técnicas precisam ser escolhidas de acordo com o que se pretende que os alunos aprendam. Como o processo de aprendizagem abrange o desenvolvimento intelectual, afetivo, o desenvolvimento de competências e de atitudes, pode-se deduzir que a tecnologia a ser usada deverá ser variada e adequada a esses objetivos. Não podemos ter esperança de que uma ou duas técnicas, repetidas à exaustão, deem conta de incentivar e caminhar toda a aprendizagem esperada. [8]

Como mostra a Tabela 7, houve diferenças substanciais no que se refere ao uso de TICs, em parte devido ao conteúdo de cada um, em parte devido à experiência já mencionada:

Tabela 7 - Uso das tecnologias da informação e comunicação nos cursos

\begin{tabular}{lccccc}
\hline & ATIVIDADES NO MOODLE & \multicolumn{2}{l}{ RECURSOS DA REDE } \\
\hline CURSO & Chats & Fóruns & Glossários & $\begin{array}{l}\text { Links para vídeos } \\
\text { e filmes }\end{array}$ & $\begin{array}{l}\text { Links para textos, } \\
\text { blogs e websites }\end{array}$ \\
\hline TWEW & 4 & 12 & 10 & 0 & 10 \\
\hline RMD & 0 & 22 & 0 & 20 & 14 \\
\hline
\end{tabular}

Iniciando com as atividades realizadas no próprio Moodle, os quatro chats no curso TWEW estavam previstos para acontecer aos sábados, dia que um número maior de discentes poderia acessar. A ideia de trabalhar com chats (ou situações de comunicação síncrona) visava poder, como definem Valente e Escudeiro [9], observar o discurso dos discentes para ajudá-los de forma mais individualizada, pois o discurso que cada um constrói nos chats expõe características próprias do indivíduo.

Embora todos os chats tenham sido realizados, a instabilidade na plataforma não permitiu uma efetiva comunicação e discussão sobre os tópicos, pois vários discentes durante a sessão não viam o conteúdo das mensagens alheias, além de terem que entrar no sistema várias vezes, pois eram desconectados. Dessa forma, ficou impraticável fazer o reconhecimento dos discursos. Por essa razão, e pela continuidade da instabilidade na plataforma, houve a eliminação total do uso de chats no curso RMD.

Os fóruns se revelaram a forma mais produtiva de participação e aquela na qual eles conseguiam se expressar melhor, por isso o número foi ampliado, o que está em consonância com a observação da teórica Vani Moreira Kenski* sobre EaD,

[...] em termos de avanço na reflexão coletiva e na criação de aproximações e afinidades teóricas, o fórum é o espaço central da ação na disciplina on-line. É no fórum que todos os alunos têm a grande chance - impossível no chat e na aula presencial - de dizer o que pensam e se posicionarem diante do que está sendo trabalhado no curso. Este espaço privilegiado é a essência do curso virtual porque ele é assíncrono, tem espaço aberto para a participação de todos (democrático) e as mensagens podem ser recuperadas e rediscutidas a qualquer momento, mesmo as postas na primeira semana do curso. [10]

* Esta observação da autora consta no artigo mencionado nas referências, mas não requer o uso de apud, pois o trecho foi retirado de um fórum no qual a autora participou e é transcrito no artigo de Oliveira. 
No curso TWEW houve um fórum para cada uma das 12 semanas, enquanto que para RMD o docente também criou 12 distribuídos igualmente ao longo do curso, mas permitiu que os discentes criassem fóruns paralelos que discutissem assuntos correlatos ao conteúdo. Assim, no curso RMD, o número de fóruns subiu de 12 para 22, pois dez novos puderam ser criados. Esse tipo de autonomia permitida foi bastante útil; o curso RMD contemplava discentes da área de Teatro que, em sua maioria, sugeriram a criação de fóruns relacionados a encenações, textos e ensaios fotográficos de espetáculos. Realmente houve uma maior apropriação nos fóruns, pois aqueles que não podiam interagir em uma semana recuperavam os conteúdos e as discussões na semana seguinte. Como havia também um bom compartilhamento de experiências, houve o desejo de se rediscutir temas anteriores, retornando aos fóruns. A não utilização de chat em RMD foi plenamente compensada e superada, pois nos fóruns as manifestações eram livres, sem restrições de quantidade de texto, compartilhamento de links e imagens etc.

Glossários são usados de forma bastante efetiva em cursos de idiomas para fins específicos e podem facilitar o aprendizado de novos vocábulos e estruturas linguísticas, além de ampliar a compreensão de textos. Os glossários utilizados no curso TWEW foram bastante ineficazes. A ideia inicial era que os próprios discentes, à medida que fossem lendo os textos e se deparassem com palavras desconhecidas, contribuíssem com a inclusão no glossário, que já contava com um número razoável de palavras incluídas pelo docente. Porém, isso só se efetivou no primeiro glossário, realizado na segunda semana do curso. Do segundo ao décimo, o recurso foi praticamente esquecido, apesar da constante insistência do docente para que houvesse colaboração. Ao final, verificou-se que os discentes julgavam que o glossário não era algo que lhes traria um benefício imediato, mas que poderia ser usado para a oferta do mesmo curso posteriormente, o que os desmotivou a contribuir. Por essa razão, os glossários foram eliminados completamente do curso RMD.

Para o curso TWEW não foi utilizado nenhum recurso audiovisual na rede, em parte porque o conteúdo focava no estudo de contos e peças em um ato, e por outro porque o docente, em sua primeira experiência lecionando $\mathrm{EaD}$, não julgou necessário haver uma maior variação dos recursos, o que com o andamento do curso se revelou um problema, o qual será tratado adiante. Textos, blogs e websites foram indicados entre a segunda e a décima primeira semana, ficando a primeira e a última semana reservadas para apresentação de todos e avaliação do curso, respectivamente. RMD teve um número bem mais alto para os dois recursos (audiovisuais e escritos), pois seu conteúdo requeria essa interação com cenas no Youtube - nas quais há trechos de encenações, ensaios, adaptações para filme e televisão - e blogs e websites com ensaios fotográficos de encenações e ensaios (nacionais e estrangeiros). Sete dos recursos audiovisuais foram sugeridos pelos próprios discentes e incorporados à programação.

Abaixo propõe-se uma enumeração de aspectos que puderam ser observados com o uso de TICs em TWEW e RMD, os quais deverão ser levados em conta na preparação de próximos cursos: 
1. Chats só devem ser utilizados se não houver instabilidade da plataforma, o que é difícil de garantir, pois não depende de circunstâncias técnicas nas quais os usuários podem intervir. Ademais, deve-se considerar a qualidade de conexão e a possibilidade de conseguir agregar um número razoável de pessoas no mesmo dia e mesmo horário, caso contrário é necessário fragmentar as discussões muitas vezes. Nada impede, porém, que sejam realizadas sessões de chat, por exemplo, via outros ambientes virtuais.

2. Os fóruns são a espinha dorsal dos cursos e é por meio deles que as discussões fluem com maior efetividade. $\mathrm{O}$ incentivo para que discentes sugiram a criação de fóruns é vital para a dinâmica do curso, pois essa autonomia, além de permitir a ampliação das discussões, prestigia o participante que contribui. Os cursos não devem ter estruturas rígidas que não permitam novas contribuições, e sim estruturas maleáveis, que já prevejam possíveis inserções.

3. Glossários não funcionam porque demandam muito esforço para nutri-los com informações e nem sempre são utilizados, tendo em vista que muitas vezes é mais fácil sanar uma dúvida diretamente em um website de busca (como o Google). Podem vir a funcionar se o docente se dispuser a nutri-los em sua totalidade ou tornar a inclusão de dados uma obrigatoriedade para o desempenho no curso. Porém, tendo em vista que os resultados que se podem obter desta ferramenta não são de grandes proporções, parece mais viável simplesmente não utilizá-la.

4. A utilização de links para vídeos e filmes deve ser incluída em qualquer curso, pois ajuda a evitar a repetição das mesmas ações no ambiente virtual. Por mais que os fóruns sejam o elemento aglutinador das discussões, referenciar e proporcionar a interação com conteúdos externos ao AVA torna o curso mais interessante e contribui para as discussões.

5. Da mesma forma, a utilização de links para textos, blogs e websites contribui para essa interação entre o AVA e o conteúdo "espalhado" na rede, que deve ser filtrado e organizado de acordo com a necessidade e objetivo de cada curso.

\section{À GUISA DE CONCLUSÃO}

$\mathrm{AEaD}$ tem se desenvolvido cada vez mais graças à crescente expansão das tecnologias da informação e da comunicação, sendo que a extensão universitária pode se beneficiar dela. A oferta de cursos de extensão para públicos de qualquer localidade - do país ou fora - já é uma realidade e essa possibilidade de formação deve continuar a evoluir.

As experiências obtidas dos cursos aqui relatados contribuíram para a aprendizagem dos discentes, que puderam conhecer novas obras, discutir outras que já conheciam e se aprofundar naquelas com as quais tinham mais intimidade de leitura. Contribuíram também para que o docente pudesse discuti-las com público de localidades diversas e que, embora sendo a maioria proveniente dos cursos de Letras, foi possível perceber que as formações proporcionadas pelos currículos de seus cursos são bastante diversas, gerando discussões ricas e menos (ou não) viciadas por algumas leituras normativas que buscam por interpretações "corretas" das obras, modulares, consagradas por tradições acadêmicas. 
Embora nem todas as ferramentas utilizadas tenham trazido os resultados esperados, no conjunto elas definitivamente colaboram para uma melhor integração dos discentes com os conteúdos, tornando alguns assuntos menos áridos, permitindo que a pesquisa se efetive, inclusive gerando autonomia para contribuições aos cursos. A combinação entre extensão universitária e educação a distância ainda tem um enorme potencial a ser explorado, pois como apresentado neste texto, existe público interessado por conteúdos novos e discussões enriquecedoras, e este só precisa ser "conectado", o que graças, às TICs, está se tornando cada vez mais possível, bastando haver iniciativas que pensem a integração ensino-pesquisa-extensão de forma a atingir novos horizontes em rede.

\section{REFERÊNCIAS}

[1] BELLONI, M.L. Educação a distância. 3. ed. Campinas: Autores Associados, 2003.

[2] SANTOS, E. F. G.; PAZZETTO, V. T.; CRUZ, D. M. Ambiente educacional rico em tecnologia: a busca do sentido. Disponível em: <http://reposital. cuaed.unam.mx:8080/jspui/bitstream/123456789/2412/1/o2_11.pdf $>$. Acesso em 4 set. 2013.

[3] FÓRUM DE PRÓ-REITORES DE EXTENSÃO DAS UNIVERSIDADES PÚBLICAS BRASILEIRAS. Política nacional de extensão universitária. Manaus, mai. 2012. Disponível em: <http://www.renex.org.br/documentos/2012-07-13-Politica-Nacional-de-Extensao.pdf $>$. Acesso em 25 ago. 2013.

[4] FLORES, F. T. Da Depressão às raízes do macartismo: representação de questões sócio-históricas em American blues, de Tennessee Williams. 2013. 323f. Tese (Doutorado em Letras) - Faculdade de Filosofia, Letras e Ciências Humanas, Universidade de São Paulo, São Paulo, 2013. Disponível em: <http://www.teses. usp.br/teses/disponiveis/8/8147/tde-15052013-093207/pt-br.php>. Acesso em 15 ago. 2013.

[5] FLORES, F. T. Nem só bem feitas, nem tão melodramáticas: The Children's Hour e The Little Foxes, de Lillian Hellman. 2008. 289f. Dissertação (Mestrado em Estudos Linguísticos e Literários em Inglês) - Faculdade de Filosofia, Letras e Ciências Humanas, Universidade de São Paulo, São Paulo, 2008. Disponível em: <http://www.teses.usp.br/teses/disponiveis/8/8147/tde-08072008150422/pt-br.php $>$. Acesso em 5 mai. 2013.

[6] SZONDI, Peter. Teoria do drama moderno [1880-1950]. Tradução de Luiz Sérgio Repa. São Paulo: Cosac \& Naify, 2001.

[7] KENSKI, Vani Moreira. Tecnologias e ensino presencial e a distância. Campinas: Papirus, 2008.

[8] MASETTO, M. T. Mediação pedagógica e o uso da tecnologia. In: MORAN, J. M; MASETTO, M. T.; BEHRENS, M. A. Novas tecnologias e mediação pedagógica. Campinas: Papirus. 2000. p. 133-173. 
[9] VALENTE, Luís; ESCUDEIRO, Paula. Práticas de avaliação online. In: DIAS, Ana Augusta; GOMES, Maria João. (Coord.). E-conteúdos para e-formadores. Guimarães: TecMinho, 2008. p. 152-165.

[10] OLIVEIRA, GERSON P. O fórum em um ambiente virtual de aprendizado colaborativo. Revista de Tecnologia Digital e Educação a Distância. v.2, n.1, out. 2005. Disponível em: <http://www.pucsp.br/tead/n2/pdf/artigo3.pdf>. Acesso em 15 ago. 2013.

\section{AGRADECIMENTOS}

Agradeço à Pró-Reitoria de Extensão da Universidade Federal do Vale do São Francisco pelo apoio aos cursos do projeto Narrativas e Visualidades - Cursos de Extensão em EaD por meio do Programa Institucional de Bolsas de Extensão (PIBEX).

FULVIO TORRES FLORES professor adjunto do curso de Artes Visuais da Fundação Universidade Federal do Vale do São Francisco (UNIVASF) - e-mail:fulvio.flores@univasf.edu.br 